\title{
Comparative Analysis between a Photovoltaic System with Two-Axis Solar Tracker and One with a Fixed Base
}

\author{
Omar Freddy Chamorro Atalaya ${ }^{1}$, Dora Yvonne Arce Santillan ${ }^{2}$, Martin Diaz Choque ${ }^{3}$ \\ Faculty of Engineering and Management \\ Universidad Nacional Tecnológica de Lima Sur, Lima, Perú
}

\begin{abstract}
In this article, the comparative analysis of the stored energies between a photovoltaic system with a two-axis solar tracker, controlled by Arduino with respect to the energy stored by a fixed-base photovoltaic system is done. This with the option of using electrical energy efficiently, since the optimal installation of photovoltaic systems plays an important role in its efficiency. Once the comparative analysis was performed, the performance of the photovoltaic system with solar tracker is determined to be $24.06 \%$ higher than the second fixed-base photovoltaic system. The correlational analysis was also carried out for the data collected from the stored energy with respect to time, thus determining that the photovoltaic system with a solar tracker has a low correlation of $\mathbf{0 . 3 3 4}$, given that in the solar tracker the energy stored without dependence on time or moment when the energy is captured, since, if there is a variation during the day of the direction of the sun's rays, the photovoltaic system will always seek to focus as much as possible on the sun's rays, guaranteeing sustainability in flexible storage of energy; while the fixed-base photovoltaic system has a moderate inverse correlation of $\mathbf{- 0 . 4 8 9}$, that is, as the hours of the day pass the orientation of the sun's rays changes, and in the absence of dynamism in the orientation of the solar cells (for be fixedbased), limited energy as the hours of the day increase. Taking these reference results, it is expected to implement photovoltaic system projects with solar tracker in rural areas of Peru that lack electrical services, since it is more efficient than the fixed base photovoltaic system.
\end{abstract}

Keywords-Photovoltaic system; solar cells; displacement; two axes; performance; orientation; stored energy

\section{INTRODUCTION}

Thanks to the growing need to make energy use more efficient and the imperative demand to deal with climate change, the development and implementation of alternative energy sources arises [1]. Photovoltaic solar energy is one of the energies with the greatest projection to be used worldwide. It is also the cleanest form of energy; however, the implementation of a solar panel power generation system has shown that its reliability and efficiency depend on many factors [2]. Sometimes it is believed that the productivity of a solar panel depends on the quality and price of the panel, however, there are other factors that can affect the way we use solar energy.

The output of the photovoltaic system is fundamentally affected by various environmental factors such as dust, orientation, irradiation, shading, etc. [3]. These factors are classified as own or external according to their nature of operation or environment respectively.

Climatic variations, high temperature or cell orientation, for example, can significantly affect the performance of solar panels. In relation to external factors strictly speaking, an important aspect such as the angle of inclination of the solar panel can be found, so the importance of analyzing this variable when determining the performance of a photovoltaic system is highlighted [4].

It is clear that photovoltaic systems depend on the sun as the first and most important factor, a well-done orientation is not only more aesthetically pleasing, but also implies an economic saving, since each panel watt for which the price was paid is used [5]. To achieve, in a simple way, the use of the sun as an energy resource, knowledge of the solar trajectory, the profile of the needs and the conditions of the location is essential [6].

The angle of inclination of the cell affects the solar radiation that reaches its surface. When the panel is placed perpendicularly in the direction of the sun's rays, it absorbs the maximum radiation for a certain period of time, considering this as the optimum inclination angle [7]. That is, the energy produced by a solar panel varies specifically from the time of day and the amount of sunlight it needs [8]. This angle is associated with factors such as latitude and solar radiation characteristics.

The optimum angle of inclination of the capture surfaces of a solar system is determined by many factors, including the incident radiation in the place where the installation is located, and the solar sky, where the shadow of objects that cannot be eliminated influences, like buildings, mountains, etc. [9]. In addition, the characteristics of the installation, that is, if it is unique or hybrid, autonomous or coupled to the network and the purpose of the installation, which defines the use and consumption regime [10].

In any case, the optimization of a solar system is given by the economic factor of the installation as a whole and not by the optimum efficiency of one of the parts [11]. Among the proposed methods, an expression is obtained to determine the optimum angle for a collector taking into account direct and diffuse radiation separately. The variation of the transmissivity of a glass cover with the angle of incidence is also considered. 
Also, being this technology, for several years, there are still knowledge gaps, leading to accidents, bad calculations or poorly made facilities, which then need to be corrected [12]. Hence the importance of learning enough about the sun's trajectory day by day and its displacement throughout the year [13]. Some of the mistakes are that a module or a solar panel is installed, but as the stations progress, shadows begin to arrive when it was not installed.

An element that makes the generation of photovoltaic solar energy impossible is uneven lighting or partial shading. This last element causes voltage and current mismatches that influence the performance of photovoltaic cells [14]. Partial shadow photovoltaic systems cannot function with maximum efficiency, due to the shadows cast by the surrounding structures and the cloud cover.

Generation systems that use solar panels should collect as much energy as possible in a given place, this condition requires that the surface of the solar panel, at all times be perpendicular to the sun's rays and, therefore, an optimal collection only it can be achieved if said surface is provided with a solar tracking movement [15].

Solar cells are oriented to move the structure that supports them, this displacement can be performed in one or two axes. [16] Although these systems with orientation capability according to the sun's rays turn out to be more expensive; However, it is much more profitable than the normal solar installation, since the solar energy obtained by the cells located in the followers is $20 \%$ higher than that obtained by fixed panels and represents a more profitable investment than the acquisition of a larger number of photovoltaic modules.

In this sense, this article seeks to evaluate the performance of a photovoltaic system with solar tracker with two-axis displacement capability, controlled by an electronic system with Arduino; This evaluation will be carried out by comparing the capacity of the stored energy with respect to a static-based system; These tests will be carried out at the facilities of the National Technological University of South Lima, located in the coastal area of the capital of Peru; during the days of the month of March, month considered with high level of solar radiation.

For this reason, this article is structured in four points, in which the determination of the methodology to be used, the analysis of the results obtained, the development of the discussion of the results and the presentation of the conclusions will be made.

\section{Methodology}

\section{A. Research Level}

The level of research addressed in this article is Descriptive /Correlational. It is descriptive since initially I seek to observe and quantify the stored energy, between a photovoltaic system with a solar tracker, and a static one; then by means of a comparison of stored energies expressed in watts / $\mathrm{h}$, the performance of the system under analysis is established. Descriptive research seeks to analyze variables autonomously by measuring or quantifying them based on an observation process [17].
And it is correlational, since I seek to discover the degree of association between the times in which the storage of the sun's rays occurs with respect to the energy stored by the photovoltaic system with solar tracker, which is part of the analysis units. Arias (2017) states, the utility and the main purpose of correlational studies is to know how a variable can behave knowing the behavior of other related variables [18]. That is, try to predict the approximate value that a variable will have, from the value obtained in the variable or related variables.

\section{B. Population and Sample}

The population and sample are composed of two units of analysis, the first being the photovoltaic system with stake base and the second the photovoltaic system with solar tracker with two-axis displacement capability, controlled by Arduino; it is important to specify that in order to achieve the displacement of the base of the photovoltaic system, 4 LDRs were used (Light Dependent Resistor), the same that will allow to achieve the movement of two servomotors.

\section{Technique used in Data Collection}

Since my data were collected from the quantitative type, the structured observation technique was used, since the indicators to be quantified in the unit of analysis are known. Observation is a technique that consists of observing or systematically observing by sight, some fact, phenomenon or situation that occurs in the unit of analysis, depending on preestablished research objectives [19].

The indicators to be observed were: the time in which the measurement of stored energy is performed, the angle of horizontal displacement, the angle of vertical displacement and the energies stored in both the photovoltaic system with solar tracker and with fixed base.

\section{RESULTS}

As part of the procedure, in Fig. 1, the architecture of the photovoltaic system with solar tracker is shown.

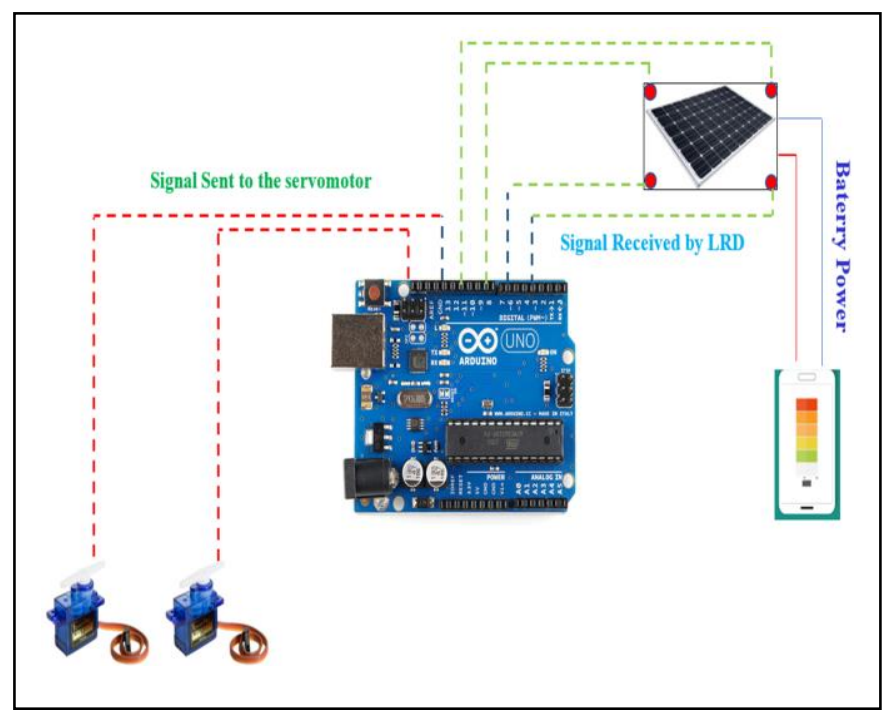

Fig. 1. Architecture of the Photovoltaic System with Solar Tracker. (Own Elaboration). 
In Fig. 1, the architecture of the solar tracking system is shown, using the Arduino-UNO software, the necessary algorithm with the programming language $\mathrm{C}$. The Arduino was used to signal the servomotor so that it turns on and can move the panel according to the direction of the light. In the following Fig. 2, the first programming segment that allows defining the angular displacement intervals of each servomotor is shown, being in this case 3 degrees; It should be noted that the first servomotor controls the movement of the base on the horizontal axis in a range of $0^{\circ}$ to $90^{\circ}$. For the second servo motor that controls vertical or azimuthal displacement, the same angular displacement resolution and the same angle of rotation were established.

The following Fig. 3 shows the second segment of the programming; here the displacement reading of the two servomotors, for which the automatic capture of the analog ohm values of each LDR; it is important to keep in mind that the ohmiaje in the LDR depends largely on the incidence of light, which falls on it.

The 4 LDRs are grouped into four different variables to perform the movement of each servomotor, the variables are called avgtop, avgbot, avgleft, avgright. To obtain the analog outputs of these variables, it was defined in the programming to make an average incidence of light in each of the LDRs as shown in Fig. 4.

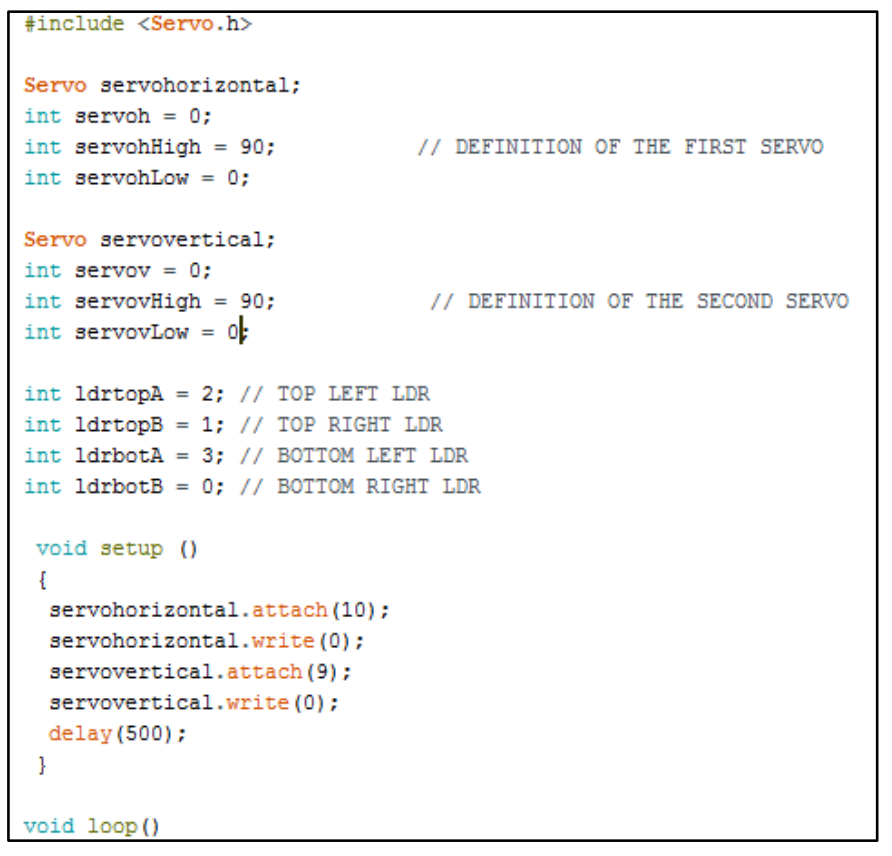

Fig. 2. First Programming Segment in the Arduino Software - UNO. (Own Elaboration).

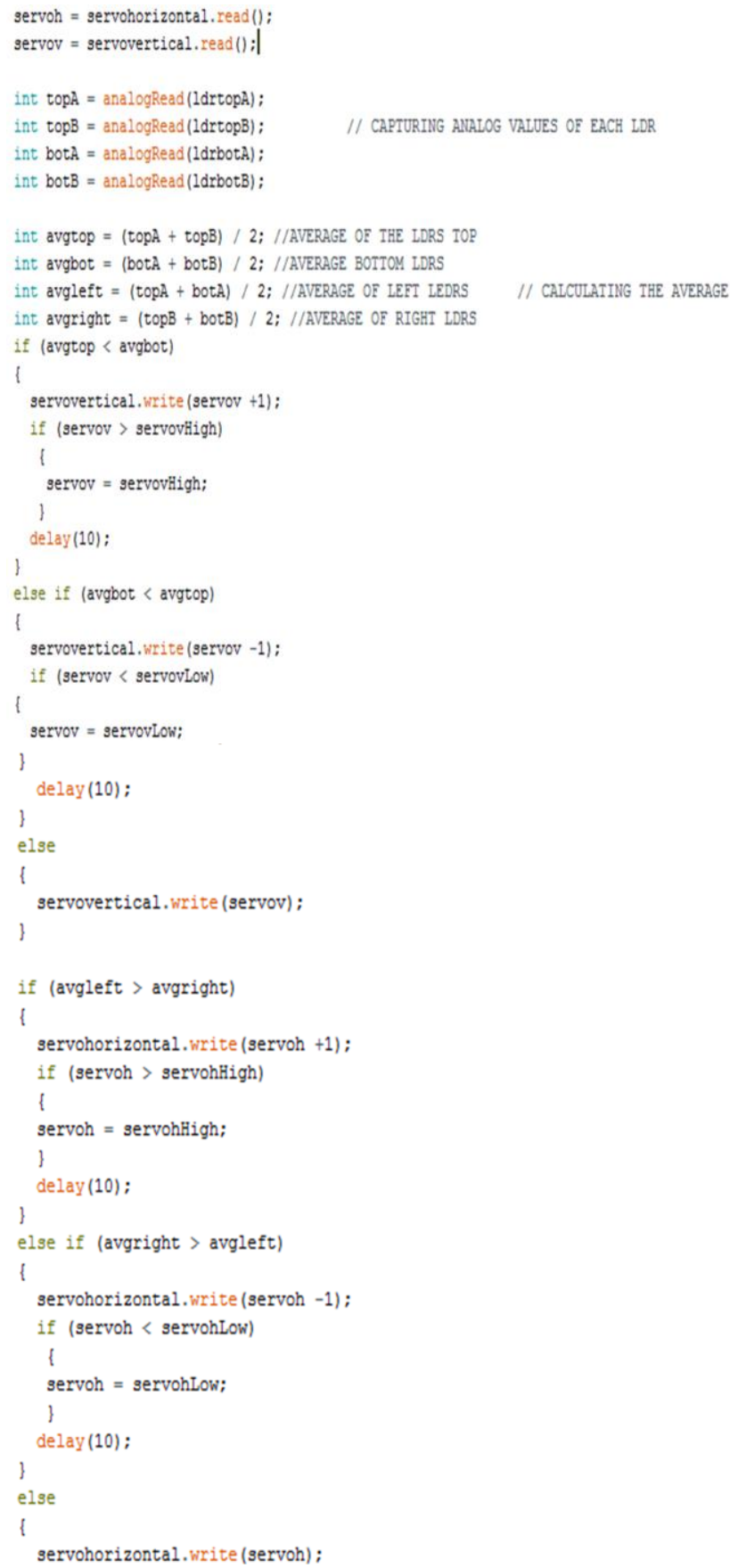

Fig. 3. Second Programming Segment in the Arduino Software - UNO (Own Elaboration). 


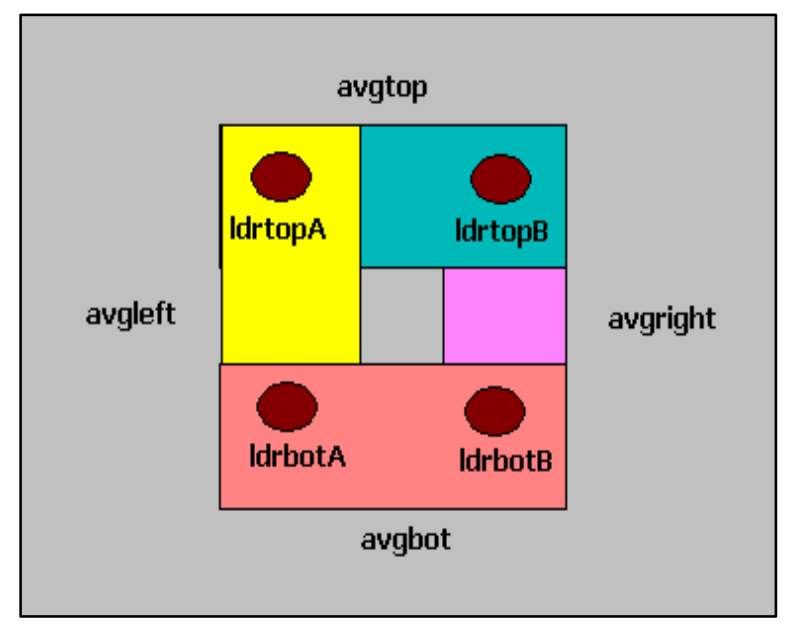

Fig. 4. LDR Distribution. (Own Elaboration).

Once the data was captured, they were analyzed, initially descriptively; for which the behavior of the energy stored by the cells with respect to time, both of the photovoltaic system with solar tracker and of the fixed base photovoltaic system was represented in Fig. 5.

In Fig. 6, it can be seen that the average of the energy stored in the fixed axis is 10.8265 , while in the photovoltaic system with solar tracker it is 13.431 .

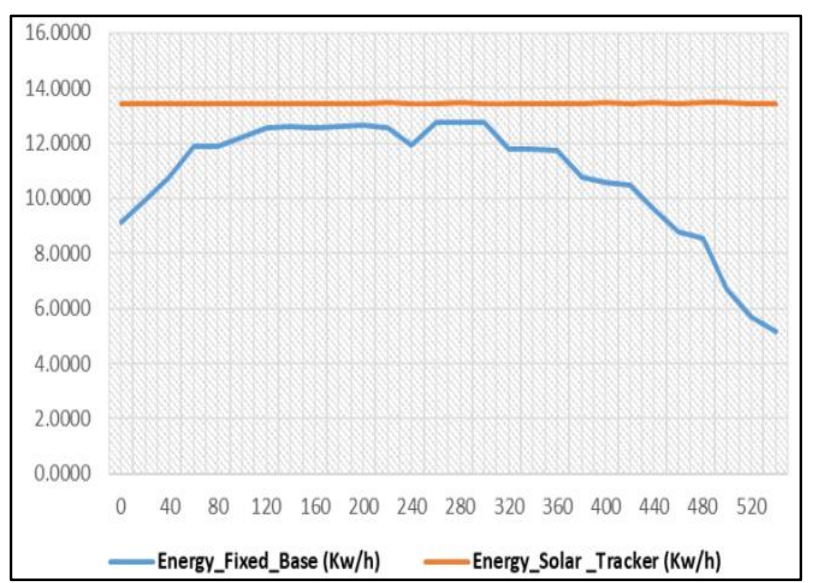

Fig. 5. Variation of the Energies Stored by the Two units of Analysis. (Own Elaboration).

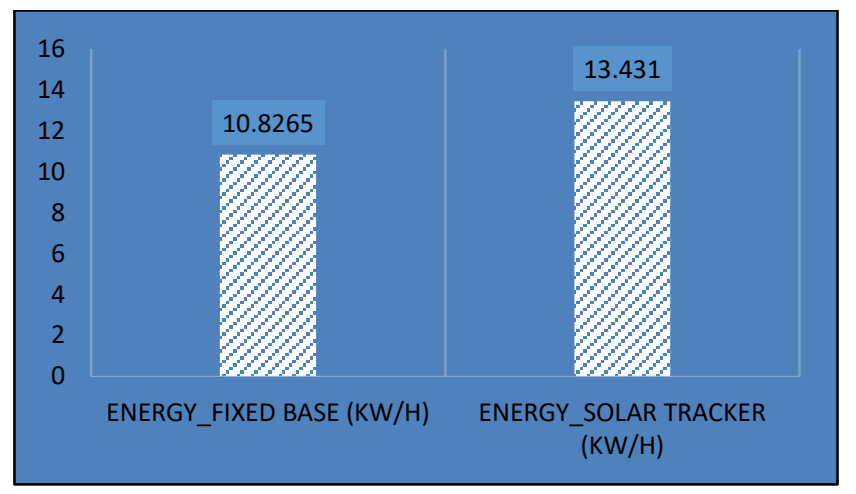

Fig. 6. Average Energy Stored in the Two Analysis units. (Own Elaboration).
Therefore, it can be concluded that the average energy stored in the photovoltaic system with solar tracker is $24.06 \%$ higher than the fixed-base photovoltaic system.

In order to determine if there is a relationship between the energy stored by the analysis units (two-axis photovoltaic system controlled by Arduino and the fixed base). The following Table I shows the Spearman test; The results show the association between the time (time of day) of the energy capture. The following Table I shows that there is a moderate inverse correlation of 0.489 between the time and energy of the warehouse by the fixed-base photovoltaic system; that is, as the hours of the day pass, the orientation of the sun's rays changes, and in the absence of dynamism in the orientation of the solar cells (controlled energy as the hours of the day increase) [20].

Table II shows the results of the correlation between time and energy stored in the photovoltaic system with the solar tracker.

On the other hand, in the correlational analysis between the energy stored by the photovoltaic system with solar tracker and the time, in which said energy is captured, it is observed that the correlation is low 0.344; since in the solar tracker the stored energy does not depend on the time or the moment in which the energy is captured, since, if there is a variation during the day of the direction of the sun's rays, the photovoltaic system will always seek to orientate itself as much as possible to the sun's rays, guaranteeing sustainability in the optimal storage of energy.

TABLE. I. SPEARMAN CORRELATION BETWEEN TIME AND ENERGY STORED BY THE FiXed BASED PHOTOVOLTAIC SYSTEM

\begin{tabular}{|c|c|c|c|c|}
\hline & & & $\begin{array}{l}\text { Time in } \\
\text { Seconds }\end{array}$ & $\begin{array}{l}\text { Energy Fixed } \\
\text { Base } \\
\end{array}$ \\
\hline \multirow{6}{*}{$\begin{array}{l}\text { Rho de } \\
\text { Spearman }\end{array}$} & \multirow{3}{*}{$\begin{array}{l}\text { Time in } \\
\text { seconds }\end{array}$} & $\begin{array}{l}\text { Correlation } \\
\text { coefficient }\end{array}$ & 1,000 &,$- 489^{* *}$ \\
\hline & & $\begin{array}{l}\text { Sig. } \\
\text { (bilateral) }\end{array}$ & . & ,008 \\
\hline & & $\mathrm{N}$ & 28 & 28 \\
\hline & \multirow{3}{*}{$\begin{array}{l}\text { Energy } \\
\text { Fixed Base }\end{array}$} & $\begin{array}{l}\text { Correlation } \\
\text { coefficient }\end{array}$ &,$- 489^{* *}$ & 1,000 \\
\hline & & $\begin{array}{l}\text { Sig. } \\
\text { (bilateral) }\end{array}$ & ,008 & \\
\hline & & $\mathrm{N}$ & 28 & 28 \\
\hline
\end{tabular}

TABLE. II. SPEARMAN CORRELATION BETWEEN TIME AND ENERGY STORED BY THE PHOTOVOLTAIC SYSTEM WITH SOLAR FOLLOWER

\begin{tabular}{|c|c|c|c|c|}
\hline & & & $\begin{array}{l}\text { Time in } \\
\text { Seconds }\end{array}$ & $\begin{array}{l}\text { Energy Solar } \\
\text { Tracker }\end{array}$ \\
\hline \multirow{6}{*}{$\begin{array}{l}\text { Rho de } \\
\text { Spearman }\end{array}$} & \multirow{3}{*}{$\begin{array}{l}\text { Time in } \\
\text { seconds }\end{array}$} & $\begin{array}{l}\text { Correlation } \\
\text { coefficient }\end{array}$ & 1,000 &, 344 \\
\hline & & $\begin{array}{l}\text { Sig. } \\
\text { (bilateral) }\end{array}$ & . &, 073 \\
\hline & & $\mathrm{N}$ & 28 & 28 \\
\hline & \multirow{3}{*}{$\begin{array}{l}\text { Energy } \\
\text { Fixed Base }\end{array}$} & $\begin{array}{l}\text { Correlation } \\
\text { coefficient }\end{array}$ &, 344 & 1,000 \\
\hline & & $\begin{array}{l}\text { Sig. } \\
\text { (bilateral) }\end{array}$ &, 073 & \\
\hline & & $\mathrm{N}$ & 28 & 28 \\
\hline
\end{tabular}


Another aspect to analyze was the dispersion model (Table III), which defines the behavior of the captured data, both of the fixed-base photovoltaic system and the photovoltaic system with solar tracker.

In Table IV, it is observed that the model that best describes the dispersion of the selected energy data stored by the fixed-base photovoltaic system is the quadratic one, whose coefficient of determination turned out to be equal to 0.969 ; The coefficients of determination of other dispersion models analyzed (linear and exponential) are also evidenced, qualifying them with a low level of determination compared to the coefficient of determination of the quadratic model.

The previous figure (Fig. 7) shows the dispersion model analyzed for the energy stored by the static photovoltaic system.

In the case of the photovoltaic system with solar tracker, in the analysis of the dispersion model of the stored energy data, it is observed in the following table, obtained from the SPSS software, that both the linear and the quadratic determination factor are low, 0.126 and 0.312 ; which can be interpreted that said energy is almost constant or rather sustainable over time; This occurs because being the dynamic base, the panels always seek the best orientation with respect to the sun's rays.

TABLE. III. ANALYSIS OF TH DISPERSION MODEL OF THE ENERGY ACCESSED By THE PHOTOVOLTAIC SYSTEM WITH A FIXED BASE

\begin{tabular}{|c|c|c|c|c|c|c|c|c|}
\hline \multirow[b]{2}{*}{ Equation } & \multicolumn{5}{|c|}{ Model Summary } & \multicolumn{3}{|c|}{ Parameter Estimates } \\
\hline & $\begin{array}{l}R \\
\text { squar } \\
e\end{array}$ & $\boldsymbol{F}$ & $\begin{array}{l}g l \\
1\end{array}$ & $\begin{array}{l}g l \\
2\end{array}$ & Sig. & $\begin{array}{l}\text { Consta } \\
n t\end{array}$ & $b 1$ & $b 2$ \\
\hline Linear &, 352 & $\begin{array}{l}14,1 \\
2\end{array}$ & 1 & 26 & $\begin{array}{l}, 00 \\
1\end{array}$ & 12,949 & $\begin{array}{l}- \\
, 00 \\
8\end{array}$ & \multirow{3}{*}{$\begin{array}{l}- \\
7,216 \mathrm{E} \\
-005\end{array}$} \\
\hline Quadratic & ,969 & $\begin{array}{l}391, \\
9\end{array}$ & 2 & 25 & $\begin{array}{l}, 00 \\
0\end{array}$ & 9,572 & $\begin{array}{l}, 03 \\
1 \\
\end{array}$ & \\
\hline $\begin{array}{l}\text { Exponenti } \\
\text { al }\end{array}$ &, 361 & $\begin{array}{l}14,6 \\
5\end{array}$ & 1 & 26 & $\begin{array}{l}, 00 \\
1\end{array}$ & 13,434 & $\begin{array}{l}- \\
, 00 \\
1\end{array}$ & \\
\hline
\end{tabular}

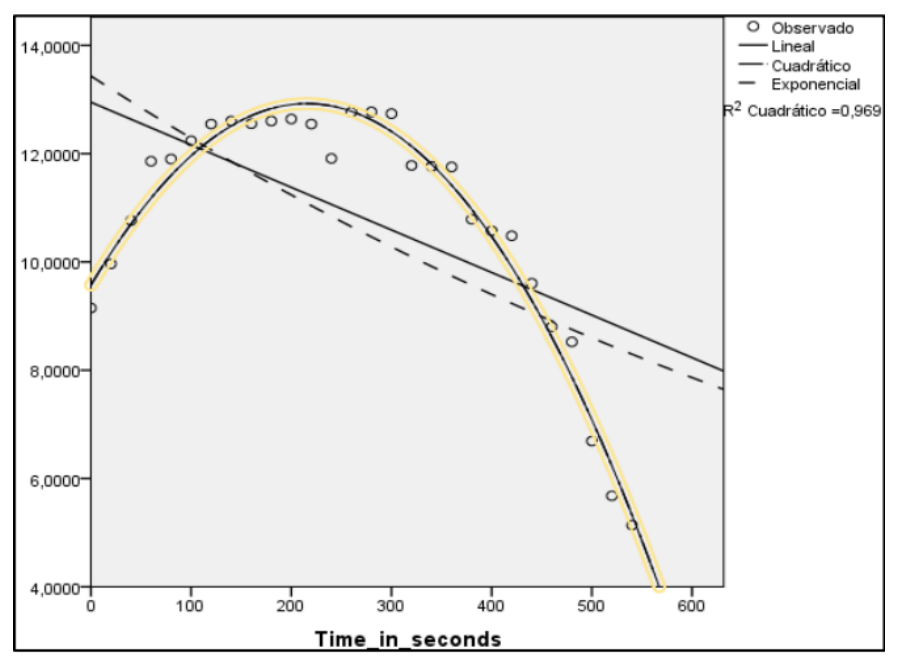

Fig. 7. Dispersion Model Analyzed for the Energy Stored by the Staticbased Photovoltaic System. (SPSS).
TABLE. IV. ANALYSIS OF TH DISPERSION MODEL OF THE ENERGY ACCESSED BY THE PHOTOVOLTAIC SYSTEM WITH A SOLAR FOLLOWER

\begin{tabular}{|c|c|c|c|c|c|c|c|c|}
\hline \multirow[b]{2}{*}{$\begin{array}{l}\text { Equatio } \\
\text { n }\end{array}$} & \multicolumn{5}{|c|}{ Model Summary } & \multicolumn{3}{|c|}{ Parameter Estimates } \\
\hline & $\begin{array}{l}R \\
\text { squar } \\
e\end{array}$ & $F$ & $\begin{array}{l}g l \\
1\end{array}$ & $\begin{array}{l}g l \\
2\end{array}$ & Sig. & $\begin{array}{l}\text { Constan } \\
t\end{array}$ & $b 1$ & $b 2$ \\
\hline Linear & ,088 & $\begin{array}{l}2,49 \\
8\end{array}$ & 1 & 26 & $\begin{array}{l}, 12 \\
6\end{array}$ & 13,424 & $\begin{array}{l}2,69 \\
1 \\
\text { E-5 }\end{array}$ & \\
\hline $\begin{array}{l}\text { Quadrati } \\
\text { c }\end{array}$ & ,089 & $\begin{array}{l}1,22 \\
0\end{array}$ & 2 & 25 & $\begin{array}{l}, 31 \\
2\end{array}$ & 13,423 & $\begin{array}{l}3,89 \\
6 \\
\text { E-5 }\end{array}$ & $\begin{array}{l}2,23 \\
1 \\
\text { E-8 }\end{array}$ \\
\hline
\end{tabular}

The following Fig. 8 shows the behavior of stored energy with respect to time; which shows that these values represent almost constant behavior during the period of observation of the data.

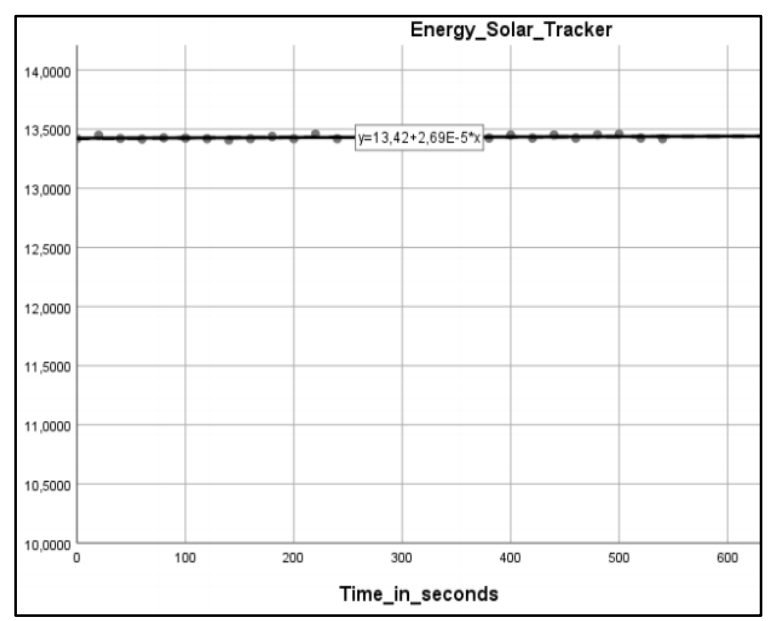

Fig. 8. Dispersion Model Analyzed for the Energy Stored by the Photovoltaic System with Solar Tracker. (SPSS).

\section{DISCUSSION}

Taking into account the results obtained, the detail is discussed below:

In relation to the comparative analysis of the energy stored between a photovoltaic system with a two-axis solar tracker controlled by Arduino analyzed in this article, with respect to another system with fixed base; the storage performance of the first photovoltaic system (with solar tracker) is $24.06 \%$ higher in relation to the second system (fixed base); So also according to Abu-Khader et al., obtained a global increase of around 30$45 \%$ in the output energy for the solar tracking system in the north-south axis $(\mathrm{N}-\mathrm{S})$, compared to a fixed photovoltaic system. On the other hand, Huang et al., Determined that, on a day with high sun, a single-axis follower can obtain $35.6 \%$ more energy compared to a fixed photovoltaic system. In addition, Kacira et al., Notes that, the average daily gain is $29.3 \%$ in solar radiation and $34.6 \%$ in power generation for a day and two-axis solar tracker with respect to a fixed cell. In that sense, we agree with the other controlled authors because there is always a higher performance between a photovoltaic system with a solar tracker in relation to a fixed one. It is important to highlight the energy values granted by the aforementioned authors are in relation to the level of solar radiation in each city [15]. 


\section{CONCLUSIONS}

From the analysis carried out in this article, the following conclusions are reached.

The energy stored by the photovoltaic system with two-axis solar tracker controlled by Arduino stored on average $2.6045 \mathrm{~W}$ $/ \mathrm{h}$, in relation to the fixed-base photovoltaic system. This was achieved using 4 LDRs, in such a way that, by capturing the incidence of the sun's rays, it sent a signal to the Arduino so that it processed said value to establish a displacement angle of two servomotors, whose displacement resolution was set to 3rd.

In the correlational analysis between the energy stored by the fixed-base photovoltaic system and the time in which said energy is captured, a moderate inverse correlation of -0.489 was obtained; while for the photovoltaic system with two-axis solar tracker, controlled by Arduino, a low correlation of 0.334 was obtained, allowing to understand that the energy stored by this last system will be almost independent of the hours of the day, since through the LDR, it will seek to guide where there is a greater incidence of solar rays.

Finally, it was determined that the linear and quadratic determination factor for the data collected from stored energy of the photovoltaic system with solar tracker, are low, around 0.088 and 0.089 ; which allows to interpret that said energy is almost constant in time; This occurs because being the dynamic base, the panels always seek the best orientation with respect to the sun's rays. While for the fixed-base photovoltaic system, the data collected responds to a quadratic dispersion model, whose determination factor is 0.969 .

\section{REFERENCES}

[1] Arencibia-Carballo, G. (2016). The importance of using solar panels in the generation electric power. España: REDVET. pp. 1-4. ISSN 16957504 .

[2] Bholt, R., Dash, R., Pradhan, A., \& Ali, S. (2015). Environmental effect assessment on performance of solar PV panel. 2015 International Conference on Circuits, Power and Computing Technologies [ICCPCT2015], 1- 5. doi:10.1109/ICCPCT.2015.7159521.

[3] Cepeda, A., \& Sierra, J. (2017). Aspects that affect panel efficiency photovoltaic and its potential solutions. Repository of the University Santo Tomás. Perú.
[4] Castañeda, J.; Mazari, I. \& Molano, M. (2019). Cost-benefit analysis of panel installation plots in the homes of the population more marginalized from Mexico. IMCO. México.

[5] Arana, L. (2016). Ubicación de los paneles solares. IMCO. México.

[6] Palacios, J. \& Morales, A. (2017). Productivity of monocrystalline solar panels, México: SOMIM 73-81, ISSN 2448-5551.

[7] Vega de Kuyper, J. C., \& Ramírez, S. (2015). Energy, renewable and non-renewable sources. México: Alfaomega grupo editor, S.A. de C,V.

[8] Vidanalage, I. \& Kaamran, R. (2017). Tilt angle optimization for maximum solar power generation of a solar power plant with mirrors. IEEE.

[9] Eliseo, S. (2019). Tilt angle by panels. Perú. Solar Energy.

[10] Minnota, M. \& Villavicencio, A. Design of alternatives for the generation of electrical energy connected to the network by means of solar energy for the almond trees building of the Universidad Javeriana Cali. Colombia: Universidad Javeriana.

[11] Obando-Paredes, E. \& Vargas-Cañas, R. (2016). Performance of an autonomous photovoltaic system against environmental conditions of a particular region. Rev. Acad. Colomb. Cienc. Ex. Fis. Nat. 40(154):2733.

[12] Manzano S.; Guevara D. \& Ríos, A. (2015). Technological Evolution of Remote Monitoring Systems in Photovoltaic Installations. Ecuador: Revista Politécnica. Vol. 36, No. 1.

[13] Gonzalez, P., Jurado, F., Granados, D. \& Ortiz, F. (2018). Analysis of efficiency and degradation of a system photovoltaic interconnected to the power grid. México: Revista Iberoamericana de Ciencias.

[14] Montano, B., Rombaoa, D., Pena, R., \& MacAbebe, E. (2016). Effects of shading on current, voltage and power output of total cross-tied photovoltaic array configuration.IeeeXplore,2016-Janua,2 6.doi:10.1109/T ENCON.2015 .7372757.

[15] Arreola, R., Quevedo, A., Castro, M., Bravo, A., \& Reyes , D. (2015). Design, construction and evaluation of a solar tracking system for a photovoltaic panel. Magazine Mexicana of Agricultural Sciences, 6(8), 1715-1727.

[16] Arrieta, D., \& Puello, S. (2015). Design and construction of a solar tracker to increase the energy efficiency in photovoltaic panels of a pumping system. Universidad of Córdova.

[17] Arias, F. (2017). The research project. Caracas: Episteme.

[18] Hernández-Sampieri, R. \& Mendoza, C (2018). Investigation methodology. Quantitative, qualitative and mixed routes (Sexta ed.). Mexico: Mac Graw Hill Education.

[19] Muñoz, C. (2015). Investigation methodology. Mexico: Oxford

[20] Pelayo, J., Luna, A., Bernabe, F., \& Guzmán, B. (2017). Comparison between the efficiency of a photovoltaic system with solar tracking and that of a fixed photovoltaic system. México: Revista Iberoamericana de las ciencias biologicas y agropecuaria. 